\title{
A Review on Teicoplanin Used as Alternative Drug to Treat the Novel Corona Virus (COVID - 19)
}

\section{Anirban Adhikary ${ }^{1 *}$, Kakoli Halder ${ }^{1}$, Debmalya Ghosh ${ }^{1}$, Snehansu Biswas $^{2}$, Indranil Chatterjee ${ }^{2}$ and Suman Kumar Nath ${ }^{2}$}

${ }^{1}$ B Pharm, Birbhum Pharmacy School, Birbhum, West Bengal, India

${ }^{2}$ Assistant Professor, Birbhum Pharmacy School, Birbhum, West Bengal, India

*Corresponding Author: Anirban Adhikary, B. Pharm, Birbhum Pharmacy School, Birbhum, West Bengal, India.
Received: August 24, 2020

Published: September 16, 2020

(C) All rights are reserved by Anirban

Adhikary., et al

\section{Abstract}

In December 2019, another coronavirus, named SARS-CoV-2, has risen up out of China causing pneumonia episodes first in the Wuhan locale and have now spread overall in view of its plausible high transmission productivity. Because of the absence of productive and explicit medicines and the need to contain the pestilence, medicate repurposing has all the earmarks of being the best instrument to discover remedial arrangement. Chloroquine, remdesivir, lopinavir, ribavirin or ritonavir have demonstrated viability to restrain coronavirus in vitro. Teicoplanin, an anti-microbial used to treat staphylococci disease, recently demonstrated adequacy to hinder the principal phase of MERS coronavirus viral cycle in human cells. This action is preserved on the SARS-Cov-2, accordingly putting teicoplanin as an expected treatment for patients with this infection.

Keywords: SARS-CoV-2; Drug Repurposing; Teicoplanin; COVID-19

\section{Introduction}

In December 2019, another coronavirus has risen up out of China causing pneumonia episodes first in the Wuhan district and have now spread overall as a result of its likely high transmission productivity [1,2]. This coronavirus, named SARS-CoV-2 (once in the past 2019-nCoV), is liable for respiratory contaminations incorporating pneumonia with a death rate evaluated $2 \%-2.5 \%$, expanding with age and the presence of fundamental ailments. On the principal long periods of March 2020, an expected 89,068 cases had been affirmed worldwide by WHO (a number likely thought little of because of the presence of asymptomatic transporters) and the epidemic has just left 3,046 dead from COVID-19 disease, most of them happening in China. Since COVID-19 is currently getting pandemic and without known approved proficient treatment, endeavors of research facilities and clinical groups have concentrated on repurposing FDA-endorsed medications to treat the most serious instances of contamination. Medication repurposing is a successful method to rapidly recognize helpful medica- tion with a realized security profile to treat a developing illness. Chloroquine/hydroxychloroquine, a cutting edge medicate utilized in the treatment and prophylaxis of jungle fever likewise utilized in immune system sickness had been appeared to restrain the replication of a few DNA and RNA infections, including a large portion of human coronaviruses [3]. As of late, chloroquine was found to restrain SARS-CoV-2 in vitro and its hydroxylated structure has been proposed as a potential treatment to treat patients tainted with SARS-CoV-2 [4,5]. In this challenge, other medication demonstrated critical adequacy against SARS-Cov-2 in vitro, for example, remdesivir, lopinavir, ribavirin or ritonavir (https://drugvirus.info/) [6]. Teicoplanin, a glycopeptide anti-microbial routinely used to treat bacterial contamination was seen as dynamic in vitro against SARS-CoV, has joined the rundown of atoms that could be utilized as remedial munititions stockpile against COVID-19 [7]. This antitoxin, right now utilized in the treatment of Gram-positive bacterial disease, particularly in Staphylococcal contaminations, has just demonstrated viability against different infections, for example, 
Ebola, flu infection, flavivirus, hepatitis C infection, HIV infection and on coronavirus, for example, MERS-CoV and SARS-CoV [8,9]. A patent was petitioned for the treatment of disease brought about by MERS-CoV in 2016 [10]. As indicated by Zhou and associates, in coronaviruses, teicoplanin follows up on the early advance of the viral life cycle by repressing the low $\mathrm{pH}$ cleavage of the viral spike protein by cathepsin $\mathrm{L}$ in the late endosomes in this way forestalling the arrival of genomic viral RNA and the continuation of infection replication cycle. An ongoing report by similar creators indicated that this movement was monitored on SARSCov-2 (the objective grouping that fill in as cleavage site for cathepsin $\mathrm{L}$ is rationed among SARS-CoV spike protein) [7]. The grouping of teicoplanin required to restrain half of infections (IC50) in vitro was $1.66 \mu \mathrm{M}$, which is a lot of lower than the fixation came to in human blood (8.78 $\mu \mathrm{M}$ for a day by day portion of $400 \mathrm{mg}$ ) [7]. These primer outcomes should be affirmed now by a randomized clinical preliminary. In light of our experience of teicoplanin use in the treatment of irresistible infections, we energize further examination of the antiviral impact of this particle on SARS-CoV-2 and propose teicoplanin as another possible option for the treatment of COVID-19 illness.

\section{Declaration of Competing Interest}

The author declares that there is no competing interest in this work.

\section{Bibliography}

1. Zhu N., et al. "A Novel Coronavirus from Patients with Pneumonia in China, 2019". The New England Journal of Medicine 382 (2020): 727-733.

2. Lai C-C., et al. "Severe acute respiratory syndrome coronavirus 2 (SARS-CoV-2) and coronavirus disease-2019 (COVID-19): The epidemic and the challenges". International Journal of Antimicrobial Agents (2020): 105924.

3. Devaux C., et al. "New insights for antiviral effects of chloroquine against coronavirus: what to expect for COVID 19?" International Journal of Antimicrobial Agents (2020).

4. Wang M., et al. "Remdesivir and chloroquine effectively inhibit the recently emerged novel coronavirus (2019-nCoV) in vitro". Cell Research (2020).

5. Colson P., et al. "Chloroquine for the 2019 novel coronavirus SARSCoV-2". International Journal of Antimicrobial Agents (2020): 105923.
6. Ko W-C., et al. "Remdesivir for SARS-CoV-2 pneumonia". International Journal of Antimicrobial Agents (2020).

7. Zhang J., et al. "Teicoplanin potently blocks the cell entry of 2019-nCoV”. BioRxiv (2020).

8. Zhou N., et al. "Glycopeptide Antibiotics Potently Inhibit Cathepsin L in the Late Endosome/Lysosome and Block the Entry of Ebola Virus, Middle East Respiratory Syndrome Coronavirus (MERS-CoV), and Severe Acute Respiratory Syndrome Coronavirus (SARS-CoV)". Journal of Biological Chemistry 291 (2016): 9218-9232.

9. Colson P and Raoult D. "Fighting viruses with antibiotics: an overlooked path". International Journal of Antimicrobial Agents 48 (2016): 349-352.

10. Pan T., et al. "Use of teicoplanin anti-middle east respiratory syndrome coronavirus". WO/2016/201692 (2015).

\section{Assets from publication with us}

- Prompt Acknowledgement after receiving the article

- Thorough Double blinded peer review

- Rapid Publication

- Issue of Publication Certificate

- High visibility of your Published work

Website: https://www.actascientific.com/

Submit Article: https://www.actascientific.com/submission.php Email us: editor@actascientific.com

Contact us: +919182824667 